\title{
Regional retrograde alteration of sub-greenschist facies chlorite to smectite
}

\author{
Fernando Nieto $^{1}$, Nicolás Velilla ${ }^{1}$, Donald R. Peacor ${ }^{2}$, and Miguel Ortega Huertas ${ }^{1}$ \\ ${ }^{1}$ Dpto. Mineralogía y Petrología and I.A.G.M. Universidad de Granada-C.S.I.C. 18002 Granada, Spain \\ ${ }^{2}$ Department of Geological Sciences, The University of Michigan, Ann Arbor, MI 48109, USA
}

Received March 31, 1993 / Accepted July 7, 1993

\begin{abstract}
Dioctahedral smectite is present as a retrograde alteration product of chlorite in Permian-Triassic red slates of the Malaguide Complex in Sierra de Espuña (Betic Cordillera). Mineral assemblages and textures, illite "crystallinity" indices, and fluid inclusion data indicate sub-greenschist facies conditions that reached at least $180^{\circ} \mathrm{C}$ in the higher-grade tectonic unit of the Malaguide Complex, preceding formation of smectite. Smectite, having $\mathrm{K}$ as the dominant interlayer cation, occurs ubiquitously intercalated with trioctahedral chlorite as thin packets of layers and as individual layers that commonly change to chlorite along layers. Although some chlorite is typically homogeneous and trioctahedral, much chlorite shows signs of alteration and has compositions corresponding to different degrees of smectite contamination. The incompatibility of metamorphic grade with the occurrence of smectite, the general association of chlorite and smectite, and the textural relations collectively show that dioctahedral smectite is derived through replacement of trioctahedral chlorite. Such replacement occurs on a regional basis and demonstrates that caution must be used in interpreting the occurrence of smectite in pelites as being due to prograde processes. Alteration of trioctahedral chlorite under oxidizing conditions due to introduction of phreatic water after uplift of the Betic Cordillera is proposed as the cause of formation of smectite.
\end{abstract}

\section{Introduction}

Retrograde metamorphic reactions are commonly observed in regionally metamorphosed rocks that have been metamorphosed at greenschist facies and highertemperature conditions. In such cases, optical scale textural characteristics and the presence of mineral assemblages corresponding to grades lower than that of peak metamorphism provide evidence for retrograde reac-

Correspondence to: F. Nieto tions. Identification of retrograde reactions in sub-greenschist facies rocks seldom occurs, however, and it is commonly assumed that metamorphism ubiquitously occurs in a prograde direction. This is in part a result of the small-grain size for such rocks, especially pelites, wherein textural relations are observed only with difficulty, the small range of temperature for such prograde sequences, and the common occurrence of metastable phases retained from lower-temperature conditions; e.g., shales may contain detrital micas, authigenic micas derived from early burial metamorphism, and metamorphic micas derived through tectonic stress (e.g., Li et al., in press), all in complex textural relations which are commonly not resolvable with optical methods. Thus smectite is commonly retained as a partially reacted mineral in highergrade rocks subject to prograde diagenesis/metamorphism.

The possibility of retrograde reactions in such rocks has been hypothesized, for example, by Frey (1987, Fig. 1-1) who noted that such reactions are one of three ways in which rocks may attain conditions of very low grade metamorphism. Nevertheless, Frey's emphasis was on prograde transformations. We are, in fact, not aware of any significant studies of the retrograde portions of $P$-T- $t$ paths for rocks formed under sub-greenschist conditions.

Most studies of fine-grained, low-grade pelitic rocks are based on X-ray diffraction (XRD) data. Such data generally cannot distinguish between different origins of the same mineral (e.g., detrital vs authigenic mica). Even where XRD may provide data on formation of a given mineral in more than one event (e.g., authigenic illite vs muscovite), such relations cannot be distinguished as prograde or retrograde because of the lack of observations of textural relations. Only where mineral assemblages are found to be inconsistent with regional trends can retrograde relations be distinguished. In contrast to optical and XRD studies, transmission electron microscopy (TEM) is capable of determining the structures (through selected area electron diffraction, SAED), compositions (through analytical electron microscopy, AEM) 
of individual crystals in fine-grained rocks, and the detailed textural relations among them (through TEM images). Each may then be correlated with a specific event, e.g., as done by Li et al. (in press), who recognized mica of five different origins in a single mudstone. Jiang et al. (1990 and references therein) have discussed the alteration of higher-grade mica to lower-grade illite/smectite (I/S) or smectite. On the basis of TEM/AEM data, they showed that hydrothermal alteration had caused "backreaction" of white mica to $\mathrm{R} 1 \mathrm{I} / \mathrm{S}$ (rectorite) in some Welsh shales for which XRD data had shown coexistence of an expandable clay mineral with mica, a relation ordinarily interpretable as being caused by prograde reactions. However, that retrograde reaction was observed to have occurred only on a local basis, overprinted on shales which were part of a well-defined regionally developed prograde sequence. Nevertheless, those relations implied that caution should be used in interpreting relations among 2:1 clay minerals as being caused by prograde reactions even on a regional basis.

Our attention was called to the possibility of regionally developed retrograde reactions by an XRD study of an apparent prograde sequence of sediments of the Malaguide Complex in Sierra de Espuña, Spain. Illite crystallinity, general mineralogical relations, and fluid inclusion data indicated that smectite occurred on a widespread, regional basis in rocks for which the regionally achieved maximum grade was much higher than that generally attributed to smectite. Mellini et al. (1991) demonstrated that retrograde reactions had affected greenschist facies rocks of related origins, with alteration of chlorite, implying the presence of regionally developed fluids that could account for the unusual occurrence of smectite. Although the distribution of smectite on a regional basis suggested its origin through retrograde reactions involving prograde clay minerals such as illite, the occurrence of such a retrograde reaction on a large scale was unprecedented and problematical. Therefore, through determination of the textural, structural, and chemical relations among the minerals, we have carried out a study of a sequence of samples, emphasizing TEM/ AEM data, with the aim of determining the origins of the individual clay minerals and of understanding the processes by which retrograde reactions occur. Those results, which demonstrate that smectite and other minerals have indeed formed through "back-reaction" of a low-grade prograde sequence, are described in detail here.

\section{Geological setting}

The Sierra de Espuña is located in the Internal Zones of the Betic Cordilleras, which make up the Alpine chain of southern Spain. Three large tectonic complexes have been distinguished in the Betic Internal Zones. They are known as the Nevado-Filabride, Alpujarride and Malaguide Complexes, in ascending tectonic order (Fig. 1). Each of these complexes is characterized by the superposition of several thrust nappes, which are in turn made up of tectonic units varying in number according to sector. In the Espuña area, several Malaguide tectonic units outcrop. They are composed of materials unaffected by metamorphism or affected only by very low grade metamorphism. They are superimposed on Alpujarride units characterized by low-grade metamorphism (Makel 1981).

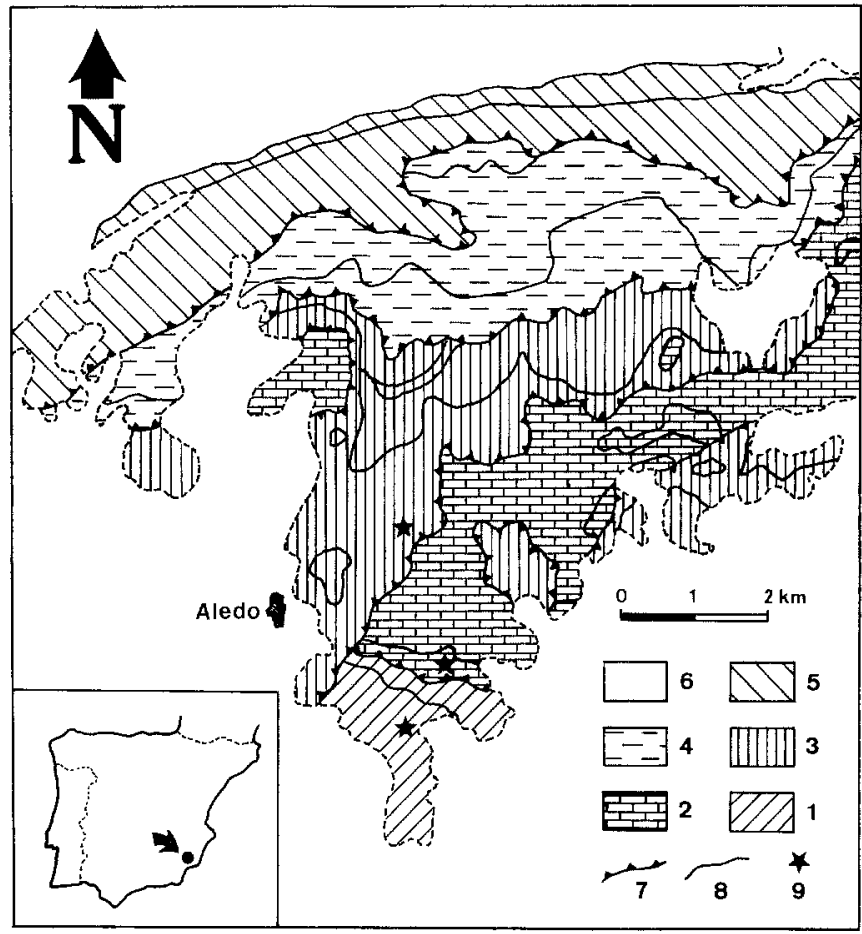

Fig. 1. Geological map (modified from Makel and Rondeel 1979) and location of the study area. Alpujarride Complex: 1, Upper Alpujarride Unit. Malaguide Complex: 2, Santa-Yechar Unit; 3, Morron Largo Unit; 4, Atalaya Unit; 5, Morron de Totana Unit; 6, Post-Triassic rocks; 7 , thrust contact between tectonic units; 8 , contact between detrital Permian-Triassic formations and carbonate Triassic formations; 9 , sample location

The samples studied here correspond to the two lowest tectonic units of the Malaguide Complex, known as the Santa-Yechar and Morron Largo Units, as defined in the IGME map (1974), and which have been subjected to the highest degree of metamorphism. Both the Santa-Yechar and Morron Largo units include two formations (Makel and Rondeel 1979): (a) a Permian-Triassic formation, composed of conglomerates, sandstones and pelitic rocks; and (b) an upper carbonate Triassic formation, in which dolomites predominate.

A general characteristic of the Permian-Triassic Malaguide formations is the widespread predominance of medium- and even coarse-grained detrital rocks (sandstones and conglomerates) overlying clay-bearing rocks. However, the proportions of clay minerals in the latter are relatively small, and most of them should be classified as semipelitic rocks.

The Kubler crystallinity indices gradually decrease from values of $0.72^{\circ} \Delta 2 \theta$ in the rocks of the upper part of the Morron Largo Unit, corresponding to conditions of diagenesis, to values of $0.30^{\circ} \Delta 2 \theta$ in the basal part of the Santa-Yechar Unit, that are typical of anchizonal conditions (Fig. 2). In addition, data of fluid inclusions occurring in the quartz of small quartz-chlorite veins, located in the upper part of the Permian-Triassic formation of the SantaYechar Unit, reveal homogenization temperatures of $180-200^{\circ} \mathrm{C}$. Such temperatures are consistent with crystallinity values, as correlated by Kisch (1987).

\section{Methods}

\section{$X$-ray diffraction}

Clean, unaltered samples were taken well below the surface and away from joints to avoid possible weathering effect. Samples were 
carefully washed and, after coarse crushing, homogeneous chips of rock were used for the XRD analyses Whole samples, clay fractions, and silt fractions were studied by X-ray diffraction (XRD) using a Philips PW 1710 X-ray diffractometer equipped with graphite monochromator and automatic divergence slit, and using $\mathrm{CuK} \alpha$ radiation. The clay and silt fractions were separated by repeated extraction of the supernatant liquid subsequent to settling. Sample preparation and determination of illite crystallinity (IC) values were carried out as recommended by the IGCP 294 IC working group (Kisch 1991). Step scanning was used, with measurement of peak widths using computer-stored data. The IC values corresponding to the limits of the anchizone as determined with our diffractometer are 0.36 and $0.23^{\circ} \Delta 2 \theta$ and were obtained using the interlaboratory standards of Kisch and some samples for which XRD data were obtained in Prof. Kubler's laboratory at Neuchâtel.

\section{Electron microscopy}

Samples representative of each of the five groups defined by X-ray diffraction (Fig. 2) were prepared as "sticky wax"-backed thin sections oriented approximately normal to the dominant planar fabric. After study by optical microscopy, carbon-coated samples were examined by scanning electron microscopy (SEM), using back-scattered electron (BSE) imaging and energy-dispersive X-ray (EDX) analysis to obtain textural information in preparation for obtaining selected areas for TEM study. Smectite-rich samples ES-2 and ES53 were chosen as representative of the Morron Largo and SantaYechar Units, respectively, and sample ES-5 was chosen for comparative purposes because it contained no detectable smectite. Three millimeter diameter aluminum washers were attached with epoxy to the areas of interest. The washers with attached thin section areas were then detached, and the samples ion-milled and carbon-coated for TEM observation using a Philips CM-12 microscope fitted with a Kevex Quantum solid-state detector. Lattice fringe images, selected area electron diffraction patterns and EDX quantitative microanalyses were obtained at $120 \mathrm{kV}$. Reflections with $d$-values $>4 \AA$ were used to obtain lattice fringe images. Microanalyses were carried out in STEM mode using a $50 \AA$ beam diameter and a scanning area of $200 \times 1000 \AA$ chosen to include a single clay mineral grain as defined by TEM and scanning images. Muscovite, clinochlore, albite, fayalite, and titanite were used to obtain k-factors to correct EDX data by the thin-film method of Lorimer and Cliff (1976).

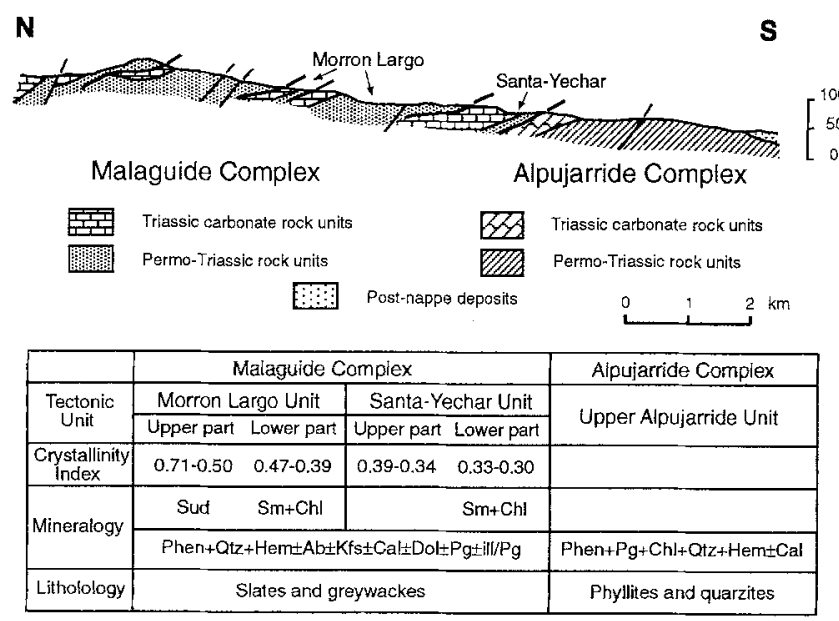

Fig. 2. Geological section (modified from Makel 1981) and mineral data for the studied area. Mineral associations do not necessarily represent equilibrium assemblages. Mineral abbreviations after Kretz (1983); Chl, trioctahedral chlorite; Sud, sudoite; Phen, phengite; $S m$, smectite

\section{Results}

\section{$X$-ray diffraction}

XRD patterns of bulk samples show that phengite or illite, quartz, and hematite occur in all the samples, whereas chlorite, smectite, paragonite, mixed-layer illiteparagonite, feldspars, calcite, or dolomite are present in some samples. Samples from the Malaguide Complex may be divided among four groups, based on mineral assemblages, illite "crystallinity" indices, and geological setting. Those groups are described in Fig. 2 for the upper and lower parts of the Morron Largo and Santa-Yechar Units.

Figure 2 emphasizes the important relation between di-trioctahedral sudoite, trioctahedral chlorite, and smectite (see below, in part, for data leading to identifications). Smectite is only present in those samples containing trioctahedral chlorite, i.e., in the lower parts of both Units of the Malaguide Complex. In the upper part of the Morron Largo Unit, sudoite, a di-trioctahedral chlorite, recognized by means of AEM and XRD data according to Fransolet and Schreyer's (1984) criteria, is present instead of trioctahedral chlorite, and smectite is absent. In the upper part of the Santa-Yechar Unit smectite and chlorite are absent.

Illite crystallinity values for both parts of the Morron Largo Unit correspond to the diagenetic zone (range $0.71-0.39^{\circ} \Delta 2 \theta$ ), whereas values for the Santa-Yechar Unit (range $0.39-0.30^{\circ} \Delta 2 \theta$ ) correspond in general to the upper part of the anchizone.

The XRD pattern of smectite displays a perfectly rational sequence of basal reflections giving values of $d(001)$ of $12.3 \AA$ and $17 \AA$ for air-dried and ethylene glycoltreated samples, respectively.

\section{Sample descriptions}

Sample ES-2 belongs to the basal part of the Morron Largo Unit. It is chlorite-rich slate in which quartz-rich and phyllosilicate-rich domains alternate on a thin section scale. The average crystal size is $10 \mu \mathrm{m}$. The BSE image (Fig. 3) of a phyllosilicate-rich domain shows grains of white mica and chlorite, with occasional prismatic crystals of rutile. The mica and chlorite are preferentially oriented parallel to a well-developed slaty cleavage that is clearly visible in hand specimen. They are therefore inferred to have formed by crystallization during the formation of slaty cleavage.

Randomly oriented mica and chlorite, likewise inferred to have formed during cleavage development, also occur in quartz-rich domains consisting of 20 to $50 \mu \mathrm{m}$ diameter grains. Large ( $200 \mu \mathrm{m}$ diameter) grains of mica with irregular shapes are randomly dispersed throughout the quartz and are inferred to have shapes inherited from a detrital source. Accessory minerals include tourmaline, zircon, and dispersed iron oxy/hydroxides.

Sample ES-53 is a quartz-rich slate with well-developed cleavage from the basal part of the Santa-Yechar Unit. It is more homogeneous than the sample described 


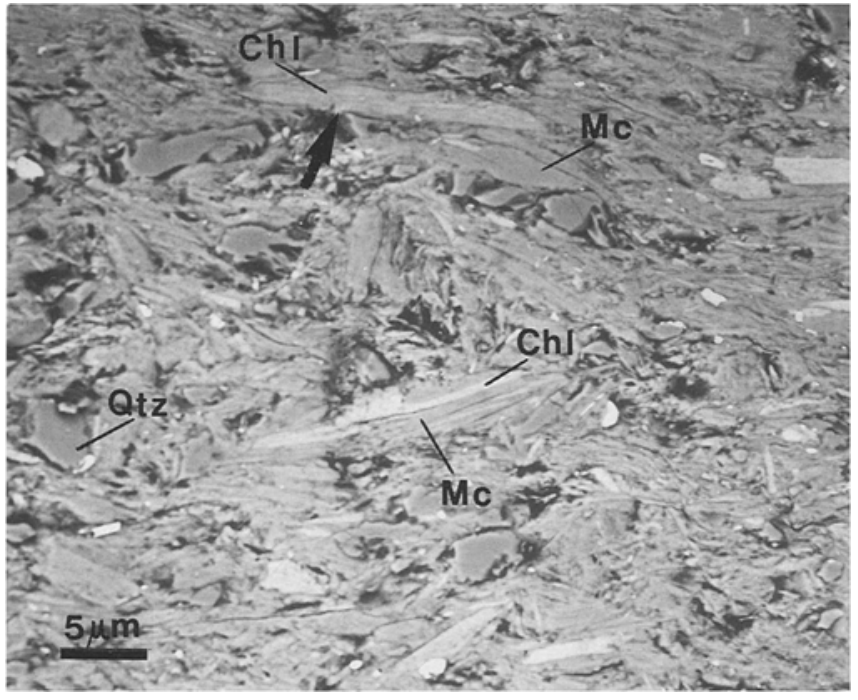

Fig. 3. Backscattered electron image representative of the texture of sample ES-2. Arrow indicates a chlorite crystal with significant K content due to smectite alteration. $C h l$, chlorite; $M c$, mica and $Q t z$, quartz

above, with no differentiation of quartz- and phyllosilicate-rich domains. It is made up of elongated quartz grains and crystals of white mica and, to a lesser extent, chlorite, all of which range from 50 to $200 \mu \mathrm{m}$ in size and are preferentially oriented in a matrix consisting largely of phyllosilicates. The matrix consists largely of very small $(<10-15 \mu \mathrm{m}$ diameter) grains of phengite and chlorite. A small proportion of iron oxy/hydroxides causes the hand sample to have a brown color. Dispersed crystals of plagioclase, K-feldspar, tourmaline, zircon, and opaque iron oxides are also present.
Sample ES-5 is a quartz-rich slate from the upper part of the Morron Largo Unit. Subangular quartz grains (20 $40 \mu \mathrm{m}$ in size) are disoriented and homogeneously distributed. The very fine grained matrix consists of small crystals of white mica and chlorite $(<10 \mu \mathrm{m}$ long). The sample shows an incipient slaty cleavage, but the preferential orientation of the phyllosilicates can be observed only with difficulty with an optical microscope. Ubiquitous iron oxy/hydroxides produce a deep red color.

\section{Transmission electron microscopy}

Three different phyllosilicates (chlorite, smectite and dioctahedral mica) were recognized in the matrix of samples ES-2 and ES-53, based on SAED patterns, EDX analyses, and lattice images. In both samples they form sub-parallel intergrowths of packets containing a variable number of layers. However, sample ES-53 is made up of larger and more crystalline packets than ES-2, as consistent with its higher grade. Nevertheless, smectite packets are thin, slightly curved and of uniform size in both cases, and are invariably closely associated with chlorite.

Smectite and dioctahedral mica both give SAED patterns with 001 sequences based on $d(001)=10 \AA$, but they are readily distinguishable on the basis of even qualitative AEM spectra, SAED patterns, and lattice fringe images. The AEM spectra of smectite imply significantly smaller $\mathrm{Al} / \mathrm{Si}$ ratios and proportions of interlayer cations than for mica. The SAED reflections are sharp and well defined for mica, as is also true for chlorite, but for smectite they are very diffuse. Furthermore, they are elongated in a direction normal to $\mathrm{c}^{*}$ (Fig. 4 inset), as consistent with some curvature of layers. Smectite is easily recog-

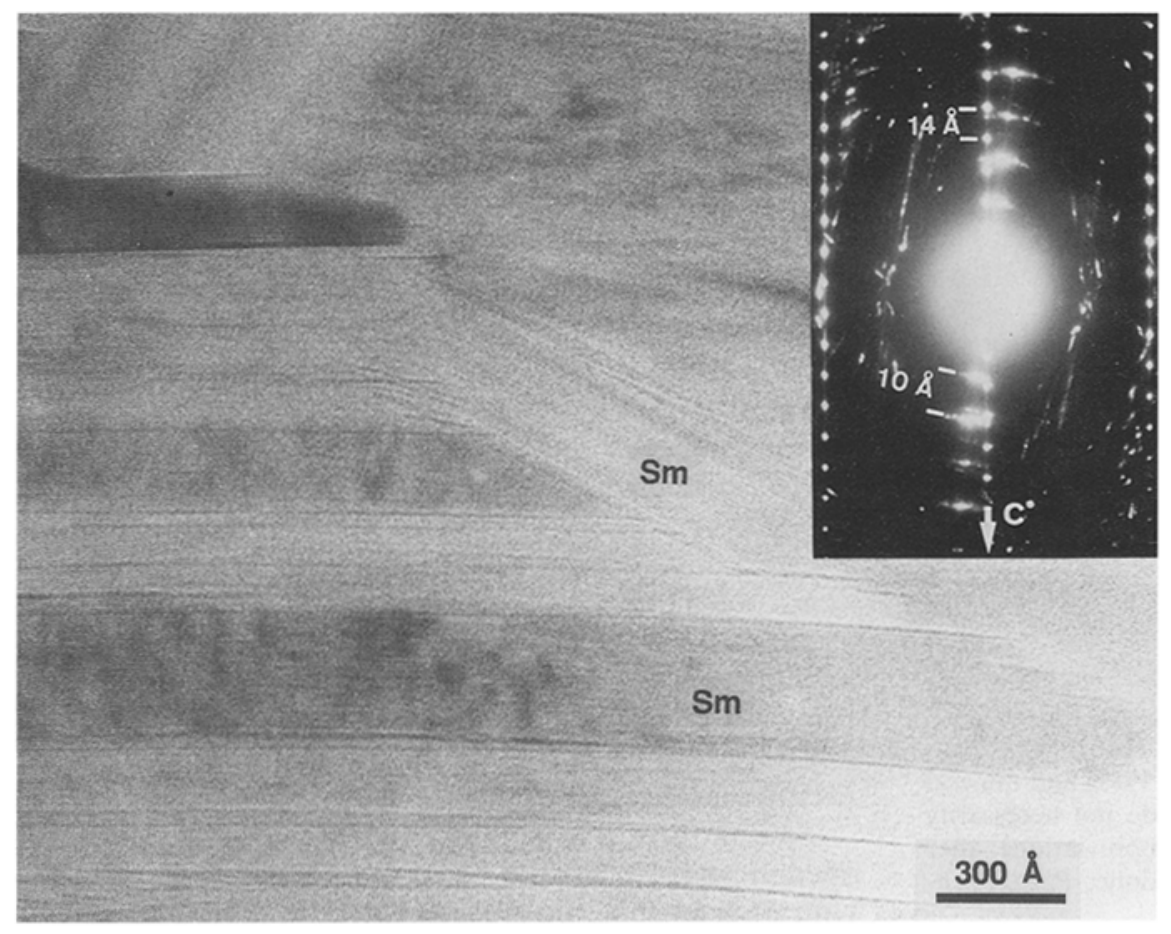

Fig. 4. Image representative of smectite packets. Inset SAED pattern showing chlorite, smectite and mica reflections 


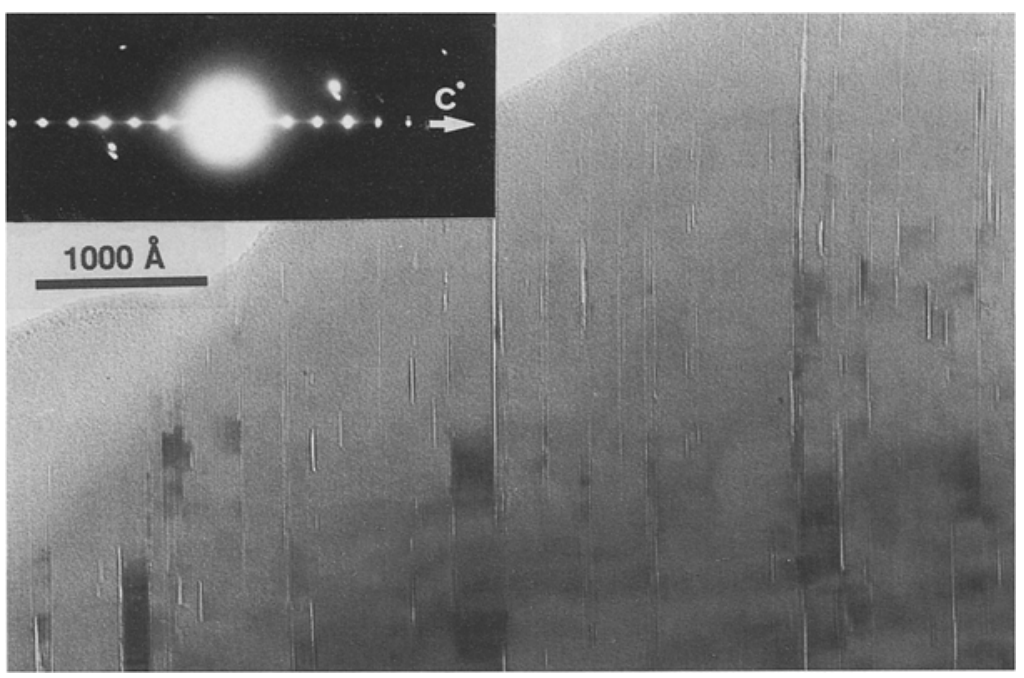

Fig. 5. TEM image and SAED pattern (inset) representative of altered chlorite. The chlorite reflections are slightly streaked along $\mathrm{c}^{*}$, and some fringes of the TEM image are separated, presumably along altered layers
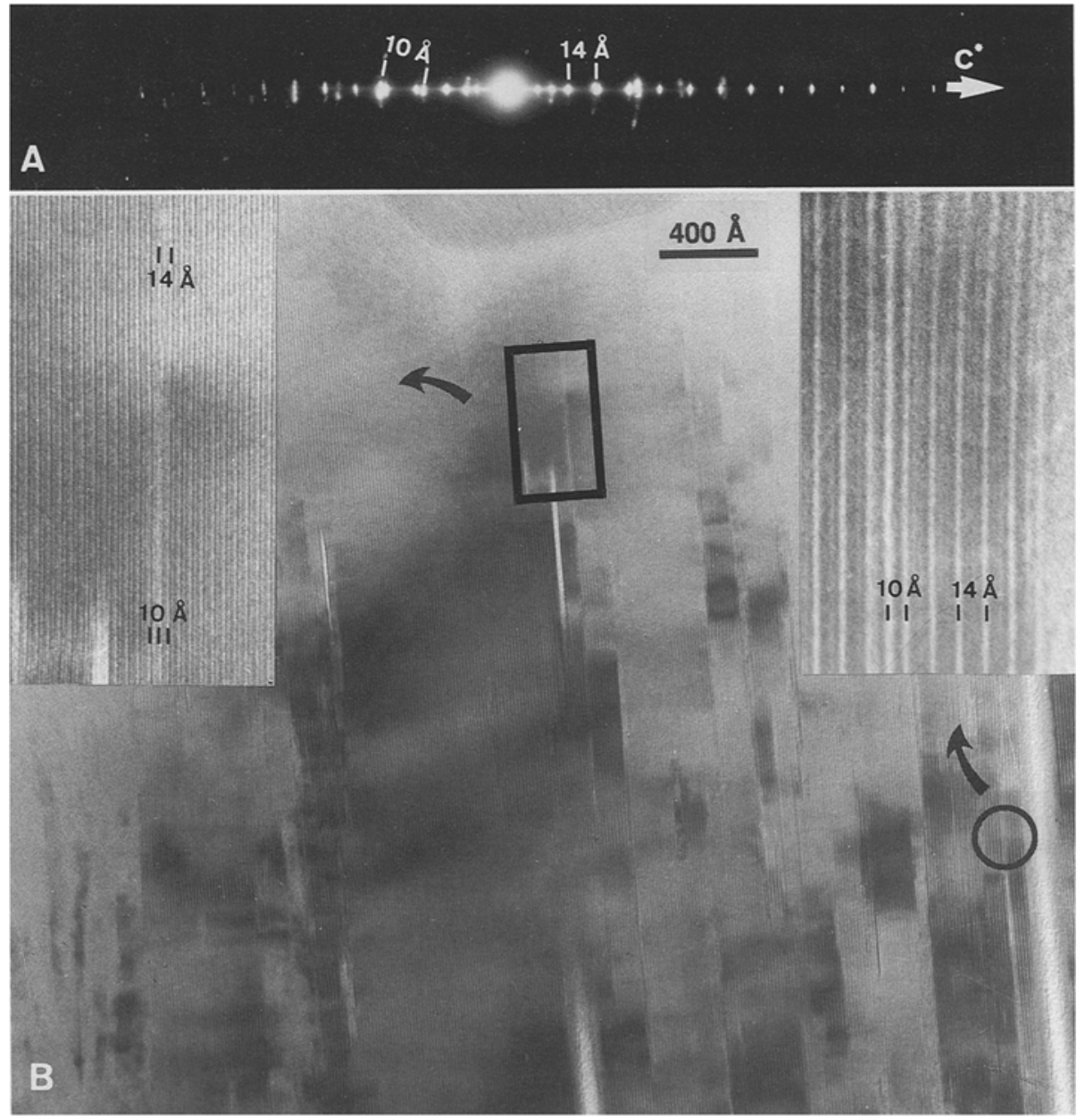

Fig. 6. A SAED pattern of altered chlorite partially transformed to smectite. B Lattice fringe image showing 14 to $10 \AA$ layer transformation (left inset) and individual $10 \AA$ layers (right inset) nized in lattice fringe images because packets have lighter contrast and ill-defined lattice fringes, they are slightly curved and thin, they have a characteristic contrast, and are rapidly damaged when exposed to the electron beam. When photographs were obtained, a second photograph of the same area was taken some minutes later to verify identification through the characteristic beam damage of smectite. Lattice fringe images of mica packets consist of perfectly straight fringes of constant spacing, have very few layer terminations as is the case for images of chlorite, and have a characteristic "mottled" contrast. The SAED patterns of mica from sample ES-2 usually show the presence of more than one row of non-(001) reflections. This feature was not observed in SAED patterns of 


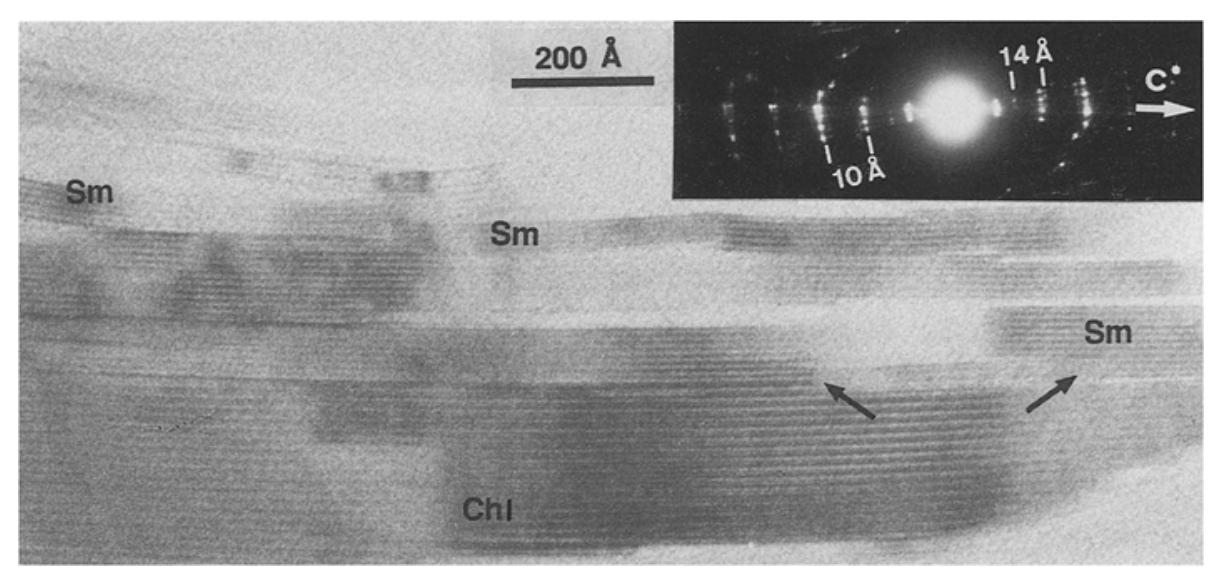

Fig. 7. Lattice fringe image of smectite packets interstratified with chlorite. Arrows point out a transformation from a $14 \AA$ fringe on the left to a $10 \AA$ one on the right micas of sample ES-53. However, in both cases mica was observed to be a monoclinic $20 \AA$ polytype (presumably $2 \mathrm{M}_{1}$ ). In addition, TEM images of both samples revealed the frequent presence of large defect-free, crystals of mica with near end-member muscovite compositions with much smaller Fe and $\mathrm{Mg}$ contents than those of the matrix mica of metamorphic origin. Such large crystals were therefore inferred to be of detrital origin.

The chlorite consists of relatively large packets of coherent layers giving well-defined lattice fringes, but signs of alteration are apparent in several features (Fig. 5). First, 001 SAED patterns display streaking parallel to $\mathrm{c}^{*}$ (Fig. 5 inset). Individual $10 \AA$ layers are infrequently observed within chlorite packets (right circle in Fig. 6), and are inferred to contribute to the streaking. Such individual layers cannot be identified with precision, but can at least be assumed to correspond to a $2: 1$ phyllosilicate, and textural relations collectively imply that they correspond to smectite. Fissures between separated layers are a form of beam damage, but such damage is closely associated with the alteration features.

Several instances were observed where individual fringes with $10 \AA$ spacings occurred within packets of $14 \AA$ fringes, and where the $10 \AA$ fringes changed alonglayer to $14 \AA$ fringes. Such a relation is illustrated in the left rectangle of Fig. 6 . It can be interpreted in several ways. For example, $10 \AA$ mica layers of primary origin have been observed to be interlayered with chlorite (e.g., Lee et a1. 1984), but where mica is well defined in TEM images of the present study, there is no indication of mixed layering; indeed mica and chlorite generally occur in separate, well-defined packets. Such interlayering is also common among trioctahedral mixed-layered chlorite/saponite (corrensite) clays, but they occur only in altered basic igneous rocks of low grade (e.g., Shau et al. 1990). Because the chlorite is intimately intergrown with packets of smectite (Fig. 7), it is much more likely that the individual $10 \AA$ fringes correspond to dehydrated, collapsed smectite layers. In part because smectite cannot occur under the same relatively high temperature conditions corresponding to formation of the metamorphic chlorite (see discussion below), the along-layer 10 to $14 \AA$ changes in fringe spacings are inferred to represent the interface between primary chlorite layers and secondary smectite layers that replace chlorite. Such alteration relations have been observed for a number of phyllosilicates (e.g., Ahn and Peacor 1987; Banfield and Eggleton 1988).

In order to obtain preferentially oriented grains with (001) normal to the beam, part of sample ES-53 was crushed in a mortar and pestle and crystallites were dispersed on a holey $\mathrm{C}$-coated $\mathrm{Cu}$ grid. The composition of some grains, as determined by AEM analysis, is intermediate to those of chlorite and smectite (see below). Pairs of spots occur that have $d(100)$ and $d(010)$ values corresponding, respectively, to trioctahedral and dioctahedral phyllosilicates. The nearly identical orientation of both lattices is consistent with coherent interfaces.

Sample ES-5, whose metamorphic grade is equivalent to that of sample ES-2, was also studied in order to serve as a standard of comparison for observations of sample ES-2. No smectite or trioctahedral chlorite were detected using TEM/AEM observations, as consistent with a lack of detection of those minerals in XRD patterns. Sudoite plays the same textural role as chlorite in sample ES-2, but alteration features are not present.

\section{Analytical electron microscopy}

Figure 8 contains data regarding composition of the phyllosilicates of the two smectite-bearing samples, plotted on triangular diagrams in terms of atomic Si, Al(total), and $(\mathrm{Fe}+\mathrm{Mg})$. Triangles represent chlorite that displayed obvious alteration signs in lattice fringe images; such analyses of chlorite have significant $\mathrm{K}+\mathrm{Na}+\mathrm{Ca}$. Two of the points corresponding to altered chlorite in sample ES-53 represent analyses of chlorite crystals whose SAED patterns demonstrate the presence of both di- and trioctahedral phyllosilicates (smectite and chlorite respectively, as shown by XRD, SAED, and AEM data). Chlorite that does not display signs of alteration, and for which analyses do not show significant $\mathrm{Na}, \mathrm{K}$, or $\mathrm{Ca}$, is represented by crosses. Chlorite that shows no signs of alteration gives analyses that correspond to nearly ideal trioctahedral chlorite with approximately six octahedral cations when normalized to 14 anions (i.e., nearly ideal trioctahedral occupancy), and ${ }^{[4]} \mathrm{Al}$ nearly equal to ${ }^{[6]} \mathrm{Al}$, as required by charge balance. Smectite and 
Table 1. Smectite formulae; normalization to 11 oxygens

\begin{tabular}{|c|c|c|c|c|c|c|c|}
\hline & $\mathrm{ES}-2,3$ & $\mathrm{ES}-2,6$ & $\mathrm{ES}-2,7^{\mathrm{a}}$ & ES-53,3 & ES-53,17 & ES-53,18 & ES-53,48 \\
\hline $\mathrm{Si}$ & 3.77 & 4.06 & 3.76 & 3.62 & 3.98 & 3.72 & 3.60 \\
\hline $\mathrm{Al}(\mathrm{IV})$ & 0.23 & 0.00 & 0.24 & 0.38 & 0.02 & 0.28 & 0.40 \\
\hline $\mathrm{Al}(\mathrm{VI})$ & 1.78 & 1.60 & 1.17 & 1.75 & 1.39 & 1.59 & 1.80 \\
\hline $\mathrm{Fe}$ & 0.13 & 0.13 & 0.56 & 0.12 & 0.19 & 0.14 & 0.12 \\
\hline $\mathrm{Mg}$ & 0.18 & 0.26 & 0.56 & 0.26 & 0.40 & 0.29 & 0.19 \\
\hline$\Sigma$ & 2.09 & 1.99 & 2.29 & 2.13 & 1.98 & 2.02 & 2.11 \\
\hline $\mathrm{Na}$ & 0.06 & 0.00 & 0.05 & 0.07 & 0.36 & 0.27 & 0.05 \\
\hline $\mathrm{Ca}$ & 0.00 & 0.00 & 0.00 & 0.00 & 0.05 & 0.09 & 0.00 \\
\hline$\Sigma$ & 0.52 & 0.41 & 0.47 & 0.66 & 0.62 & 0.71 & 0.79 \\
\hline
\end{tabular}

a Some contamination of chlorite
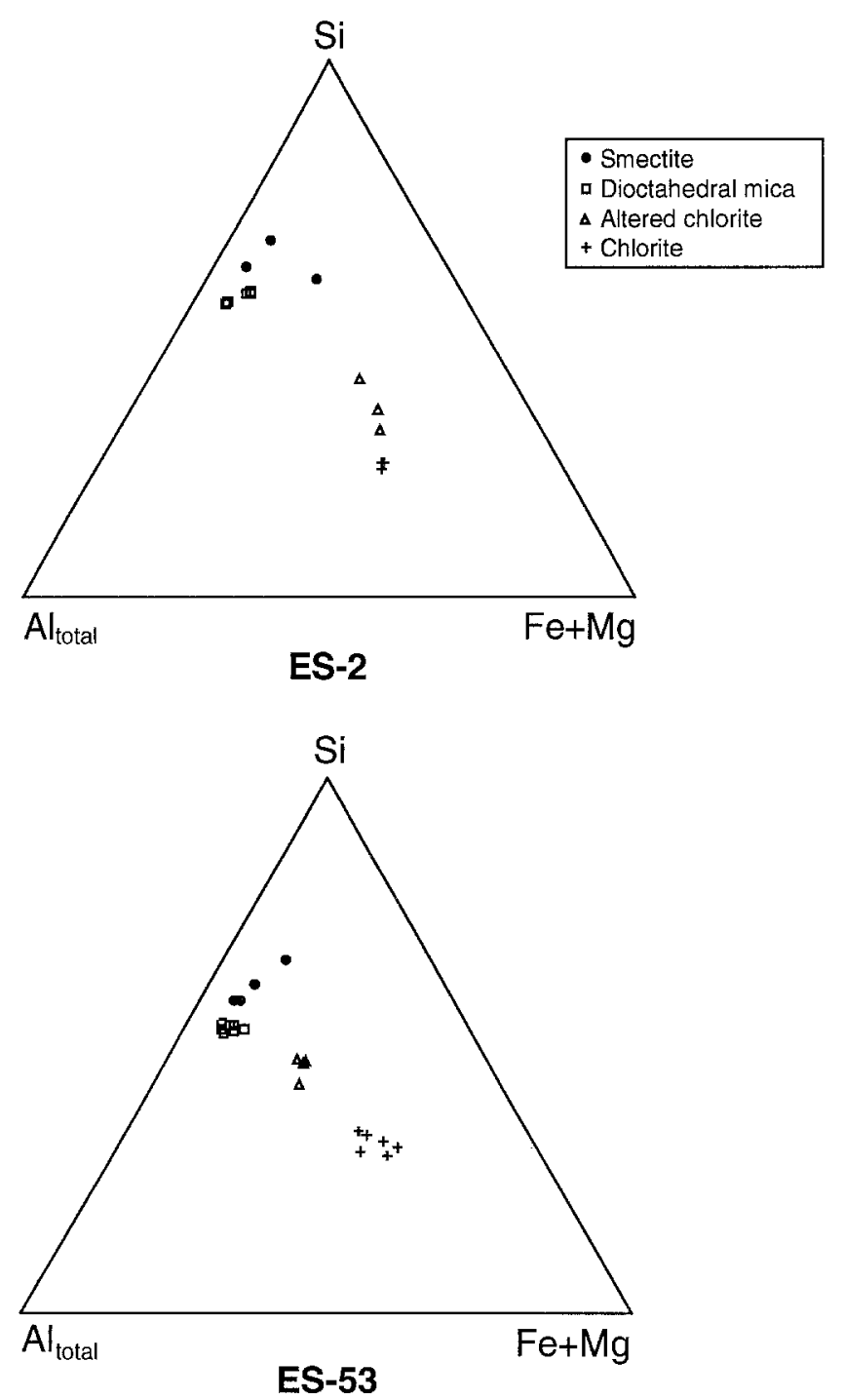

Fig. 8. Plot of chemical composition data for phyllosilicates as determined by AEM. Partially altered chlorite analytical data plot at positions intermediate to those of homogeneous smectite and chlorite phengite are distinguished by the higher Si content of the former.

The most significant aspect of Fig. 8 is in the relative positions of unaltered chlorite, altered chlorite, and smectite. The analytical data for altered chlorite plot directly between those of chlorite and smectite. This implies that the apparent incipient alteration seen in TEM images of some chlorite does indeed reflect the presence of some smectite, even though only $14 \AA$ fringes are seen in most lattice fringe images.

Smectite formulae are typical of smectite from other localities (Table 1) in having ${ }^{[4]} \mathrm{Si}$ contents approaching four, significant octahedral $\mathrm{Mg}$ and $\mathrm{Fe}$, and interlayer cation contents of approximately 0.4 . The smectite is unusual, however, in that the interlayer sites are dominated by $\mathrm{K}$, rather than $\mathrm{Na}$ or $\mathrm{Ca}$ as normally is the case. Freed and Peacor (1989) have noted that smectite with $\mathrm{K}$ as the dominant interlayer cation may be the rule rather than the exception in sediments that have undergone diagenesis or low-grade metamorphism. Some smectite of sample ES- 53 contains significant $\mathrm{Na}$ accompanied by small proportions of $\mathrm{Ca}$ (Table 1), but even in those cases the proportion of $\mathrm{K}$ is large. No Ca was detected in the smectite of sample ES-2.

\section{Discussion}

There are two possible origins for smectite in sub-greenschist facies rocks: (1) As detrital material having originated as a terrestrial weathering product, or as a product of alteration of detrital volcanic glass or other phases during the incipient stages of sediment diagenesis; such smectite may be retained through the lowest-temperature stages of diagenesis or low-grade metamorphism. (2) As a product of reaction of fluids and phyllosilicates of prograde metamorphic origin at a time later than, and at a temperature lower than that of peak metamorphism; i.e., as a retrograde alteration product. The smectite of the Sierra Espuna slates must have the latter origin, as implied by the following relations:

1. The textures of the samples as imaged by SEM and TEM, even those of the samples of lowest grade, are clearly typical of a metamorphic rock. In particular, chlo- 
rite and mica are aligned parallel to slaty cleavage and thus have an origin through growth with basal planes normal to the directed tectonic stress. Such "metamorphic" mica and chlorite have been shown to have an origin through dissolution of illite and chlorite that had a bedding-parallel orientation that was, in turn, derived through earlier (lower-temperature) reaction of detrital smectite (e.g., Li et al., in press). The metamorphic micas typically are mature, having $2 \mathrm{M}_{1}$ polytypes and compositions approaching those of ideal mica, as opposed to earlier illite that is a $1 \mathrm{M}_{\mathrm{d}}$ polytype and that is alkali deficient and ${ }^{[4]} \mathrm{Al}$-poor relative to mica (Peacor 1992). The illite "crystallinity" index implies a minimum of anchizone grade, at least for the Santa-Yechar rocks, as consistent with the textural and mineralogical data. The occurrence of smectite in rocks of relatively high grade is further indicated by its occurrences in trace amounts, detected by XRD, even in greenschist-facies phyllites of the closely related Alpujarride Complex. Smectite in shales is unstable at the temperatures corresponding to metamorphism which, according to the fluid inclusion data, reached at least $180^{\circ} \mathrm{C}$. Indeed, it is generally agreed that smectite undergoes a reaction for which illite or illite/ smectite $(\mathrm{I} / \mathrm{S})$ is a reactant during burial metamorphism at temperatures that do not exceed approximately $100^{\circ} \mathrm{C}$ (Freed and Peacor 1989). Such illite or I/S transforms, in turn, through tectonically induced stress at higher temperatures to mica. Thus, the peak metamorphic conditions corresponding to the studied rocks are incompatible with the occurrence of detrital smectite or smectite that originated during very early diagenesis from alteration of detrital precursors such as volcanic ash.

2. Smectite only occurs in those rocks containing trioctahedral chlorite, and always in close association with such chlorite, as seen in TEM images. Rocks that have di-trioctahedral sudoite as the chlorite species contain no smectite. Indeed, where smectite occurs in packets that are large enough to permit unambiguous identification, it ubiquitously occurs as packets interlayered with chlorite. Such packets of $10 \AA$ layers are closely associated with individual $10 \AA$ layers that occur within packets of $14 \AA$ chlorite. The individual $10 \AA$ layers are therefore inferred to correspond to dehydrated smectite. Such individual layers are infrequently observed to change, along-layer, to a $14 \AA$ layer. The collective data therefore imply that such a change corresponds to the interface between primary chlorite and secondary smectite. Detrital smectite generally has a very characteristic appearance, occurring in mudstones as "megacrystals" made up of parallel to sub-parallel, discontinuous, anastomosing, wavy layers having variable spacings and contrast in TEM images (e.g., Ahn and Peacor 1986). Such smectite is heterogeneous in composition. Thus, the smectites of the Sierra Espuña samples not only have specific textures indicating replacement of chlorite, but they do not have the characteristics of detrital smectite. In addition, there are no significant differences in composition between the smectite of the two different metamorphic units, as consistent with a homogeneous source.

3. Chlorite occurs as relatively large grains oriented with (001) parallel to cleavage. When not associated with smectite, such chlorite has an appearance typical of that of metamorphic chlorite, with straight $14 \AA$ fringes, sharp reflections in SAED patterns, a generally homogeneous appearance, and a composition typical of ideal trioctahedral chlorite, i.e., it has nearly six octahedral cations and nearly equal ${ }^{[4]} \mathrm{Al}$ and ${ }^{[6]} \mathrm{Al}$, as consistent with charge balance requirements. However, the chlorite that is closely associated with packets of smectite commonly has a heterogeneous appearance in part marked by elongated fissures produced by separation of layers due to electron beam damage. Such separations are commonly associated with atom diffusion at the sites of defects, or by $\mathrm{H}_{2} \mathrm{O}$ loss. In either event, we infer that they are initiated along interlayers that are smectite-like, and that are caused by the incipient alteration of chlorite to smectite. Such a relation is confirmed by AEM analyses, which show that such heterogeneous material has a composition that is intermediate to those of chlorite and smectite. In addition, the sum of octahedral cations implies a dioctahedral content, and ${ }^{[4]} \mathrm{Al}$ and ${ }^{[6]} \mathrm{Al}$ are significantly different, both characteristics being associated with interlayering of dioctahedral 2:1 layers in dominantly trioctahedral chlorite (Shau et al. 1990).

These relations therefore collectively imply that the smectite has been derived by alteration of primary metamorphic chlorite. To our knowledge, this is the first example of such retrograde replacement of chlorite by smectite. Although Jiang et al. (1990) showed that smectite could form through retrograde reactions in anchizone-grade pelites, they demonstrated replacement of dioctahedral metamorphic mica by dioctahedral R1 I/S (rectorite). In addition, that reaction was inferred to occur only locally within an otherwise normal prograde sequence. The reaction in the Sierra de Espuña is unusual in that it involved retrograde reaction on a regional basis.

At first sight, replacement of a trioctahedral $\mathrm{Mg}, \mathrm{Fe}$ rich mineral by a dioctahedral Al-rich mineral seems to be unusual, especially insofar as the studied rocks contain unaltered dioctahedral mica, and because the di-trioctahedral sudoite of other rocks was unaffected. It generally has been assumed on the basis of the assumption of a layer by layer alteration mechanism for phyllosilicates that dioctahedral and trioctahedral layer minerals each transform to the same kinds of structures. Moreover, experimental alteration of chlorite has produced trioctahedral smectite, vermiculite or trioctahedral mixed-layer minerals in all cases (Makumbi and Herbillon 1972; Ross 1975; Ross and Kodama 1974, 1976). However, those experiments were carried out in closed systems, with chlorite as the only initial mineral and with no possibility of incorporation of other elements or of reactions with other phases, as is usual in natural systems.

On the other hand, Ahn and Peacor (1987) have studied biotite schists from New Zealand that were altered at temperatures much lower than, and occurring much later than, those of peak metamorphism. In that case, dioctahedral kaolinite was shown to have replaced trioctahedral biotite in a reaction involving replacement of a single layer of biotite by two layers of kaolinite. The along-layer linear interfaces where kaolinite changed to biotite, within a packet of parallel biotite layers, were inferred to be 
channels along which reactant and product ions and $\mathrm{H}_{2} \mathrm{O}$ were transported. Although the flux of reactants and products depends on the details of the reaction, it was clear that $\mathrm{Al}$ was added, whereas $\mathrm{Mg}, \mathrm{Fe}$ were lost. The biotite was clearly unstable in the presence of the pore fluids serving as a source and sink for ions. Thus, introduction of a fluid of composition different from that corresponding to formation of trioctahedral chlorite at peak metamorphic conditions is required to produce such a reaction.

We likewise postulate introduction of a pore fluid postdating peak metamorphism that served as a source for reactant ions and a sink for product ions for the rocks of this study. Although the reaction can be written in several ways, depending upon which element is assumed to be conserved, all reactions require the introduction of $\mathrm{Si}$ and $\mathrm{K}$ and loss of $\mathrm{Mg}$ and $\mathrm{Fe}$. The along-layer transitions are seen as points in two-dimensional TEM images, but must be linear features in three dimensions. Such linear imperfections must represent transitions from one structure to the other along which ions and $\mathrm{H}_{2} \mathrm{O}$ are transported. The reaction is visualized as involving dissolution of chlorite on one side of such an interface and crystallization of smectite on the other, with reactants and products transported along the interface that serves as a connection to reservoirs of pore fluids. Because neither dioctahedral mica in altered rocks nor sudoite in other rocks were affected by alteration, the driving force for the reaction must have been related to the difference in composition between trioctahedral chlorite and fluids. That is, replacement of trioctahedral chlorite by a dioctahedral clay mineral is entirely reasonable, given appropriate fluid compositions.

Packets of several biotite layers were observed to be replaced by packets of kaolinite layers, and similar relations have been observed for a number of other systems (Ahn and Peacor 1987, and references therein). Such a relation was inferred to result from simultaneous alonglayer reaction of entire packets. The reaction was inferred to be similar to that involving individual layers in most respects. The packets of smectite layers that are intercalated with chlorite are interpreted as having a similar origin. Alteration, once initiated at the edge of a chlorite crystal, must progress along layers whether involving one or several layers, but the reaction is never observed to proceed with a component normal to layers.

Because the exact timing of alteration is unknown, we cannot associate it with a specific event that may have caused introduction of fluids on a regional scale. However, we speculate that the introduction of phreatic water into the system after uplift of the Betic Cordillera should produce a reactive environment in which chlorite, due to its $\mathrm{Fe}^{2+}$ content, would become especially sensitive to oxidation processes.

The same kind of relation was postulated by Mellini et al. (1991) for the in situ alteration of chlorite to supergene phases that include "hydrated chlorite" and smectite in the Nevado-Filabride Complex, which is the deepest structural complex of the Betic Cordillera. High resolution transmission electron microscopy studies have not been carried out on the intermediate Alpujarride Com- plex, but EPMA data indicate that "yellow-to-red phyllosilicates," as named by Mellini et al. (1991), that have biotite-like optical properties, are actually chlorite with minor quantities of $\mathrm{K}$ and $\mathrm{Na}$ (unpublished data). The rapid uplift caused by thinning of the tectonic pile by erosion and/or extensional post-metamorphic processes, which is the cause of chlorite alteration in the Nevado-Filabride Complex, could well have affected the entire metamorphic sequence, producing similar effects in both upper complexes. This chlorite alteration is not optically detectable in the Malaguide slates, as is the case in the schists of the lower complexes. Such relations serve to further emphasize the conclusions of this study, namely that retrograde alteration even of sub-greenschist facies rocks may occur on a regional basis, and that the presence of smectite need not signify prograde relations in such rocks.

Acknowledgements. This paper has been supported by Project PB920961 and BE90-234 grant to F. Nieto (DGICYT, Spain), Research Group of the Junta de Andalucía no. 4065 and NSF Grants 8817080 and 91-04565 to Donald R. Peacor. The CM-12 STEM and Hitachi SEM were purchased with support from NSF Grants EAR 87-08276, and EAR 83-14092. We are grateful to W-T Jiang and $\mathrm{Y}-\mathrm{H}$ Shau for help in the use of the STEM and for discussion concerning interpretations of data, and to M. Mellini for a critical review of the manuscript.

\section{References}

Ahn JH, Peacor DR (1986) Transmission and analytical electron microscopy of the smectite to illite transition. Clays Clay Miner 34:165-179

Ahn JH, Peacor DR (1987) Kaolinitization of biotite: TEM data and implications for an alteration mechanism. Am Mineral 72:353-356

Banfield JF, Eggleton RA (1988) Transmission electron microscope study of biotite weathering. Clays Clay Miner 36:47-60

Fransolet AM, Schreyer W (1984) Sudoite, di/trioctahedral chlorite: a stable low-temperature phase in the system $\mathrm{MgO}-\mathrm{Al}_{2} \mathrm{O}_{3}-\mathrm{SiO}_{2}$ $\mathrm{H}_{2} \mathrm{O}$. Contrib Mineral Petrol 86:409-417

Freed RL, Peacor DR (1989) Variability in temperature of the smectite/illite reaction in Gulf Coast sediments. Clay Miner 24:171180

Frey M (1987) Low temperature metamorphism. Blackie, Glasgow IGME (1974) Mapa geológico de España escala 1:50,000. Hoja 953, Lorca

Jiang WT, Peacor DR, Merriman RJ, Roberts B (1990) Transmission and analytical electron microscopic study of mixed layer illite/smectite formed as an apparent replacement product of diagenetic illite. Clays Clay Miner 38:449-468

Kisch HJ (1987) Correlation between indicators of very low-grade metamorphism. In: Frey M (ed) Low temperature metamorphism, Blackie, London, pp 227-300

Kisch HJ (1991) Illite crystallinity: recommendations on sample preparation, X-ray diffraction settings and interlaboratory samples. J Metamorphic Geol 9:665-670

Kretz R (1983) Symbols for rock-forming minerals. Am Mineral $68: 277-279$

Lee JH, Peacor DR, Lewis, DD, Wintsch RP (1984) Chiorite-illite/ muscovite interlayered and interstratified crystals: a TEM/ STEM study. Contrib Mineral Petrol 88:372-385

Li G, Peacor DR, Merriman RJ, Roberts B (in press) The diagenetic to low-grade metamorphic evolution of matrix white micas in the system muscovite-paragonite in a mudrock from Central Wales, UK. Clays Clay Miner 
Lorimer GW, Cliff G (1976) Analytical electron microscopy of minerals. In: Wenk HR (ed) Electron microscopy in mineralogy, Springer, Berlin Heidelberg New York, pp 506-519

Makel GH (1981) Differences in tectonic evolution for superposed Malaguide and Alpujarride tectonic units in the Espuña area (Betic Cordilleras Spain). Geol Mijnbouw 60:203-208

Makel GH, Rondeel HE (1979) Differences in stratigraphy and metamorphism between superposed Malaguide and Alpujarride units in the Espuña area (Betic Cordilleras, Spain). Estud Geol $35: 109-117$

Makumbi MN, Herbillon AJ (1972) Vermiculitisation experimental d'une chlorite. Bull Groupe Fr Argiles XXIV: 153-164

Mellini M, Nieto F, Alvarez F, Gómez-Pugnaire MT (1991) Micachlorite intermixing and altered chlorite from the Nevado-Filabride micaschists, Southern Spain. Eur J Mineral 3:27-38

Peacor DR (1992) Diagenesis and low-grade metamorphism of shales and slates. In: Buseck PR (ed) Minerals and reactions at the atomic scale: transmission electron microscopy. Reviews in mineralogy 27. Mineral Soc Am, Washington DC, pp 335-380

Ross GJ (1975) Experimental alteration of chlorites into vermiculites by chemical oxidation. Nature 295:133-134

Ross GJ, Kodama H (1974) Experimental transformation of a chlorite into a vermiculite. Clays Clay Miner 22:205-211

Ross GJ, Kodama H (1976) Experimental alteration of a chlorite into a regularly interstratified chlorite-vermiculite by chemical oxidation. Clays Clay Miner 24:183-190

Shau YH, Peacor DR, Essene EJ (1990) Corrensite and mixed-layer chlorite/corrensite in metabasalt from northern Taiwan: TEM/ AEM, EPMA, XRD, and optical study. Contrib Mineral Petrol 105: $123-142$

Editorial responsibility: V. Trommsdorff 